Check for updates

Cite this: Chem. Sci., 2019, 10, 3846

๑ All publication charges for this article have been paid for by the Royal Society of Chemistry

Received 29th November 2018 Accepted 27th February 2019

DOI: $10.1039 / \mathrm{c} 8 \mathrm{sc} 05328 \mathrm{f}$

rsc.li/chemical-science

\title{
Light triggers molecular shuttling in rotaxanes: control over proximity and charge recombination $\uparrow$
}

\author{
Maximilian Wolf, ${ }^{a}$ Ayumu Ogawa, ${ }^{\text {bc }}$ Mareike Bechtold, ${ }^{\text {ae }}$ Maxime Vonesch, (D) \\ Jennifer A. Wytko, (D) ${ }^{c}$ Koji Oohora, (D) ${ }^{b}$ Stéphane Campidelli, (D) ${ }^{d}$ \\ Takashi Hayashi, (D) *b Dirk M. Guldi (D) ${ }^{* a}$ and Jean Weiss (D)*c
}

\begin{abstract}
We present the synthesis of novel rotaxanes based on mechanically interlocked porphyrins and fullerene and their advanced investigations by means of photophysical measurements. To this end, a fullerenecapped dumbbell-type axle containing a central triazole was threaded through strapped (metallo) porphyrins-either a free-base or a zinc porphyrin. Femtosecond-resolved transient absorption measurements revealed charge-separation between the porphyrin and fullerene upon light excitation. Solvent polarity and solvent coordination effects induced molecular motion of the rotaxanes upon charge separation and enabled, for the first time, subtle control over the charge recombination by enabling and controlling the directionality of shuttling.
\end{abstract}

\section{Introduction}

The field of topologically sophisticated molecules and molecular motions has been the focus of renewed attention since the awarding of the Nobel Prize of chemistry to Sauvage, Stoddart, and Feringa. ${ }^{1}$ Following the first templated synthesis of a catenane $^{2}$ up until the design of devices utilizing molecular shuttles, ${ }^{3}$ lessons were learned about both the synthetic methods available to make sophisticated molecular scaffolds, ${ }^{4,5}$ and the design of properties related to molecular motions. Molecular motions in catenanes and rotaxanes have been the focus of attention for decades ${ }^{6-10}$ and theoretical investigations correlated to experiments are progressively shining light on the dynamic behavior in rotaxane structures. ${ }^{11-13}$ Several methods, such as cation, ${ }^{14}$ anion ${ }^{15}$ or guest binding,,${ }^{16} \mathrm{pH}$ changes,${ }^{17}$ redox stimuli, ${ }^{18,19}$ solvents changes ${ }^{20,21}$ and light irradiation ${ }^{22-24}$ have been envisioned to trigger motion mostly in rotaxanes. In designing molecular shuttles powered by light, inspiration is taken from nature, which uses porphyrin derivatives in chloroplasts as light harvesters and electron donors. ${ }^{25}$

${ }^{a}$ Friedrich-Alexander-Universität Erlangen-Nürnberg, Department of Chemistry and Pharmacy, Egerlandstraße 3, 91058 Erlangen, Germany. E-mail: dirk.guldi@fau.de ${ }^{b}$ Department of Applied Chemistry, Graduate School of Engineering, Osaka University, 2-1 Yamadaoka, Suita 565-0871, Japan. E-mail: thayashi@chem.eng.osaka-u.ac.jp

'Institut de Chimie de Strasbourg, UMR 7177 CNRS-Université de Strasbourg, 4, rue Blaise Pascal, 67000 Strasbourg, France. E-mail: jweiss@unistra.fr

${ }^{d}$ LICSEN, NIMBE, CEA, CNRS, Université Paris-Saclay, CEA Saclay, 91191 Gif-surYvette Cedex, France

'Institute of Inorganic Chemistry Karlsruhe Institute of Technology, Engesserstraße 15, D-76131 Karlsruhe, Germany

$\dagger$ Electronic supplementary information (ESI) available: Experimental details, additional data and graphs. CCDC 1864783. For ESI and crystallographic data in CIF or other electronic format see DOI: $10.1039 / \mathrm{c} 8 \mathrm{sc} 05328 \mathrm{f}$
Interest in interlocked photodyads has evolved over the years after initially focusing on the effects of the peculiar topology on the rate of charge separation (CS) and charge recombination. ${ }^{7}$ Combining porphyrins with $\mathrm{C}_{60}$, which is one of the best-known organic electron acceptors, has led to a plethora of electron donor-acceptor systems. ${ }^{26}$ In short, the interest in fullerenebased electron donor-acceptor systems arises from the small reorganization energy of fullerenes in electron transfer reactions. As a result, back electron transfer (BET) occurs in the Marcus inverted region and, thus, leads to long-lived chargeseparated states (CSS). ${ }^{27}$ The drawback of simple, twocomponent, electron donor-acceptor components is that BET is usually fast. By introducing additional electron donors and/or acceptors, it is possible to achieve multi-step electron transfer reactions that lead to longer-lived charge-separated state (CSS). ${ }^{28}$ Many such systems have been reported..$^{29,30}$ The disadvantage of large systems is that evaluating the deactivation pathways is non-trivial and undesired deactivation pathways are likely added as well.

These considerations led to the approach of constructing interlocked structures with a scaffold containing fullerenes and porphyrins. ${ }^{31}$ On many occasions, porphyrins and fullerenes have been utilized as stoppers in pseudorotaxanes or catenanes, but only in very few cases in rotaxanes. In none of the rotaxane cases does the photoactive porphyrin constitute the shuttle, which moves along the axle. ${ }^{32-34}$ The current work is a stepchange as it describes the preparation and the properties of a rotaxane containing a strapped porphyrin as the ring and a fullerene stopper at the end of a mobile dumbbell. The photophysical properties of the two rotaxanes, that is, $\mathbf{1}$ and $\mathbf{1 Z n}$, in which the dumbbell bears a fullerene derivative as electron acceptor and the rings respectively comprise a free-base 
porphyrin $\left(\mathrm{H}_{2} \mathrm{P}\right)$ or a zinc porphyrin $(\mathrm{ZnP})$ as the photosensitizer, are compared. In the $\mathrm{H}_{2} \mathrm{P}$-based rotaxane 1 , the dumbbell is likely to glide freely within the ring. In the presence of zinc in, for example, the porphyrin-based rotaxane $(\mathbf{1 Z n})$, the position of the dumbbell is fixed by metal-ligand coordination and can be perturbed by the use of coordinating ligands. The variation in the lifetime of the charge-separated state provides a means of detecting the gliding of the dumbbell within the strapped porphyrin ring. This work provides, to the best of our knowledge, the first example of photoactive rotaxanes in which the directional or random motion of the shuttle is triggered by an intramolecular photoinduced charge transfer. Past work was mainly based on intermolecular rather than intramolecular charge transfer, either electrochemical or photochemical. As such, the use of light enables control over energy or charge transfer processes..$^{\mathbf{6}, 35-38}$

\section{Results and discussion}

\section{Synthesis}

The rotaxanes studied in this work were prepared according to Scheme 1, using a recently reported tandem active metal templated copper alkyne-azide cyclization (CuAAC) reaction, in which zinc and copper promote the formation of dumbbells within a phenanthroline-strapped porphyrin. ${ }^{39}$ Azide stopper $\mathbf{2}^{\mathbf{4 0}}$ fullerene derivative $\mathbf{3},{ }^{\mathbf{4 1}}$ and phenanthroline-strapped porphyrin $\mathbf{4 Z n},{ }^{\mathbf{4 2 , 4 3}}$ were synthesized according to reported methods. Compounds 3, 4, and 4Zn also served as references for the photophysical studies. To prepare the free base rotaxane, first the copper(I)-phenanthroline complex of the strapped porphyrin 4Zn was generated in situ. Reaction of this complex with azide 2 and acetylene 3 , followed by removal of both the copper and zinc ions using EDTA and then $\mathrm{CF}_{3} \mathrm{CO}_{2} \mathrm{H}$, afforded free base rotaxane 1 in $48 \%$ yield. The removal of both metals from the rotaxane facilitated the purification step. The porphyrin was subsequently remetallated with zinc(II) acetate to provide rotaxane $\mathbf{1 Z n}$.

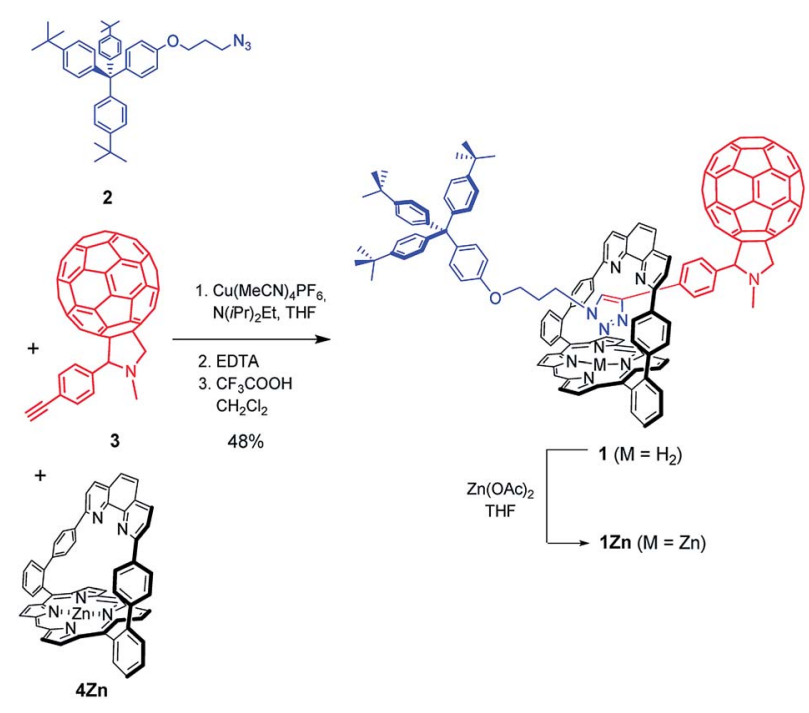

Scheme 1 Synthesis of the studied compounds.

\section{Steady-state absorption and fluorescence}

Absorption experiments were conducted with Zntetraphenylporphyrin (ZnTPP) as reference. To determine extinction coefficients, steady-state absorption spectra were measured in a concentration range from $10^{-8}$ to $10^{-6} \mathrm{M}$ to prevent aggregation, on one hand, and to stay within the boundaries of the Lambert-Beer law, on the other hand (Fig. 1).

The absorption spectra of $\mathbf{1 Z n}$ in toluene reveal the typical porphyrin features including a Soret-band absorption at $\sim 420 \mathrm{~nm}$ and two Q-band absorptions at $\sim 550$ and $590 \mathrm{~nm}$. In addition, in the UV region below $400 \mathrm{~nm}$, absorptions of the fullerene and the phenanthroline strap are discernable. Overall, all of the porphyrin absorption features are red-shifted by up to 5 nanometers in $\mathbf{1 Z n}$ relative to the ZnTPP reference. This shift is due to the complexation of triazole of the axle by the $\mathrm{Zn}$ center leading to its penta-coordination. ${ }^{43-47}$ The extinction coefficient of the Soret-band is in the range of $10^{5} \mathrm{M}^{-1} \mathrm{~cm}^{-1}$. For 1, absorption patterns typical of $\mathrm{H}_{2}$ TPP were observed in the visible region of the spectrum. Like what was seen for $\mathbf{1 Z n}$, high energy absorptions $(<400 \mathrm{~nm})$ stem from $\mathrm{C}_{60}$ and the phenanthroline strap (see ESI, $\uparrow$ Fig. S1).

Only negligible impact is seen in the absorption spectra of 1Zn in benzonitrile or in toluene, to which 500 equivalents of pyridine were added. Here, the additional red-shift is just $0.5 \mathrm{~nm}$. Notably, in pyramidal, penta-coordinated ZnPcomplexes, the $\mathrm{Zn}$-center is known to be displaced out of the porphyrin plane towards the ligand. ${ }^{\mathbf{4 4 - 4 8}}$ In turn, the Zn-center in $1 \mathrm{Zn}$ is not accessible from the top-side and strongly sterically encumbered from the bottom-side. The top-side is blocked by an overall steric hindrance stemming from the phenanthroline strap and the axle. The bottom-side lies within the inverted pyramid. Both effects result in very small binding constants for the hexa-coordination of the $\mathrm{Zn}$-center.

In the steady-state fluorescence experiments, porphyrin fluorescence quantum yields of $0.0009,0.0054$, and 0.0014 for 1Zn in toluene, chlorobenzene, and benzonitrile, respectively, indicate a nearly quantitative quenching. In comparison to

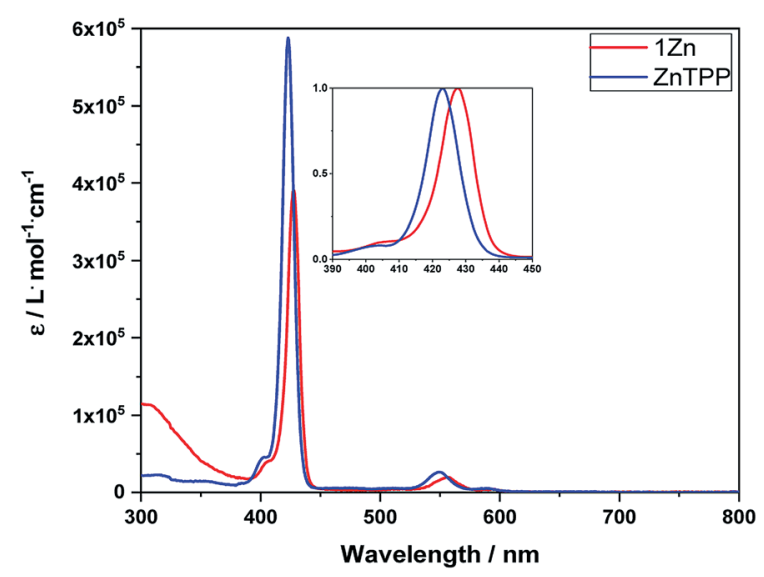

Fig. 1 Steady-state absorption spectra of 1Zn (red) and ZnTPP (blue) in toluene. Inset: Normalized Soret absorption bands to highlight the red-shifted absorption. 
reference $\mathbf{4 Z n}$, the quenching is as high as 0.97 in the aforementioned solvents. At this point, we infer the activation of nonradiative deactivation pathways, such as charge separation in 1Zn, which are absent in the $\mathrm{ZnP}$ reference. The same picture emerges for 1 (see ESI, $\uparrow$ Table S1).

\section{Electrochemistry and thermodynamic driving forces}

Square wave voltammetry was performed on $1 Z n$ in orthodichlorobenzene (o-DCB) with $0.1 \mathrm{M}$ tetrabutylammonium perchlorate as supporting electrolyte. In the potential window of $o$-DCB, e.g. from -2.50 to $1 \mathrm{~V}$ vs. $\mathrm{Ag} / \mathrm{AgNO}_{3}$, three fullerene reductions were discernable at $-2.08,-1.52$, and $-1.16 \mathrm{~V}$. In addition, the porphyrin was oxidized at +0.21 and $0.67 \mathrm{~V}$ and reduced at $-1.69 \mathrm{~V}$ (see ESI, $\uparrow$ Fig. S2).

By combining the results from the steady-state spectroscopy and electrochemistry, the thermodynamic driving forces for charge transfer, e.g. charge separation and charge recombination, were calculated. The absorption and fluorescence data were used to derive the singlet excited state energy of 1Zn as $2.09 \mathrm{eV}$. The energy of the charge-separated state was calculated using the first porphyrin oxidation and the first fullerene reduction of $\mathbf{1 Z n}$. Implicit in the difference between these values is the driving force for the charge separation from the excited state. The only correction required was for the dielectric constant of the medium as described in the literature $;^{49}$ results are presented in Table 1. For the free base rotaxane 1, analogous calculations and results are listed in the ESI, $\uparrow$ Fig. S3 and Table S2.

The triplet excited state energies of both the Zn-porphyrin and the fullerene, with values of 1.53 or $1.50 \mathrm{eV}$, respectively, ${ }^{51}$ are higher in energy than the calculated energy of the $\mathrm{ZnP}^{{ }^{+}-}-\mathrm{C}_{60}{ }^{\cdot-}$ charge-separated state in $\mathbf{1 Z n}$ in chlorobenzene and benzonitrile. As such, charge recombination is expected to populate the ground state rather than a triplet excited state. In toluene, however, the triplet excited state of the fullerene is observed as a product of charge recombination (vide infra), as the charge-separated state is increased in energy. In 1, the charge-separated state is sufficiently high in energy to populate either the triplet excited state of $\mathrm{C}_{60}$ or that of $\mathrm{H}_{2} \mathrm{P}$ (see Table S2, $\mathrm{ESI} \dagger$ ), and accordingly, charge recombination results in these states as the predominant pathway of deactivation.

\section{Transient absorption spectroscopy}

Two different experimental setups were used to photoexcite the porphyrins at their Soret-band absorptions at either at 420 or
$430 \mathrm{~nm}$. First, time delays between 0 and $6000 \mathrm{ps}$ and a time resolution of 150 fs were employed; second, time delays between $<1 \mathrm{~ns}$ and $400 \mu \mathrm{s}$ and a time resolution of $\sim 1$ ns were used.

In the ZnTPP reference, the second singlet excited state is formed instantaneously as demonstrated by its characteristic transient maxima at 450 and $580 \mathrm{~nm}$ as well as a broad absorption from 600 to $700 \mathrm{~nm}$. All of the aforementioned were accompanied by bleaching of Q-band absorptions at 555 and $595 \mathrm{~nm}$. Internal conversion (IC) with $5 \times 10^{11} \mathrm{~s}^{-1}$ and intersystem crossing (ISC) with $5 \times 10^{8} \mathrm{~s}^{-1}$ to the first singlet excited state and the triplet excited state, respectively, constitute the deactivation pathways following the initial excitation. Spectral characteristics of the first singlet excited state are transient maxima at 450, 580, 620, 700 and $1260 \mathrm{~nm}$, accompanied by transient minima at 555, 600 and $660 \mathrm{~nm}$. The minima are due to ground state bleaching and stimulated emission. For the triplet excited state, the following features were observed: a maximum at $470 \mathrm{~nm}$, ground state bleaching at 555 and $595 \mathrm{~nm}$, and a broad and featureless absorption across the visible regions, with an $840 \mathrm{~nm}$ maximum.

Based on the thermodynamics of $\mathbf{1 Z n}$, charge separation should afford the one-electron oxidized porphyrin $\left(\mathrm{ZnP}^{\cdot+}\right)$ and the one-electron reduced fullerene $\left(\mathrm{C}_{60}{ }^{-}\right)$, in addition to the deactivation cascade seen in the $\mathrm{ZnTPP}$ reference. Population of the second singlet excited state ${ }^{1 * *} \mathrm{ZnP}$ is followed by IC to the first singlet excited state ${ }^{1 *} \mathrm{ZnP}$, from where the further reaction steps occur. The corresponding excited state deactivation pathways are summarized in Fig. 2 .

Of relevance for the analysis are the fingerprint features of the one-electron oxidized porphyrin $\left(\mathrm{ZnP}^{\cdot+}\right)$ and the oneelectron reduced fullerene $\left(\mathrm{C}_{60}{ }^{-}\right)$, with peaks at 410 and $1010 \mathrm{~nm}$ respectively, ${ }^{52-54}$ where neither contributions from the porphyrin nor the fullerene excited states render the kinetic analyses ambiguous. The analysis of the transient absorption spectra was conducted with global target analysis (GTA), taking into account the aforementioned spectral and kinetical observations and calculated energetics. GTA was performed via GloTarAn, ${ }^{55}$ a graphical user interface for the statistics package TIMP $^{56}$ for R, which is especially designed for analyzing multiway spectroscopic data. Importantly, solvents of different polarity, i.e., toluene, chlorobenzene, and benzonitrile, were used. For the first two solvents, a four-species model was sufficient to fit the experimental data, whereas in benzonitrile a five-species model was necessary, which will be rationalized hereafter.

Table 1 Calculated driving forces for charge separation and charge recombination to ground state and/or triplet excited state of $1 \mathrm{Zn}-$ the dielectric constants were taken from ref. 50

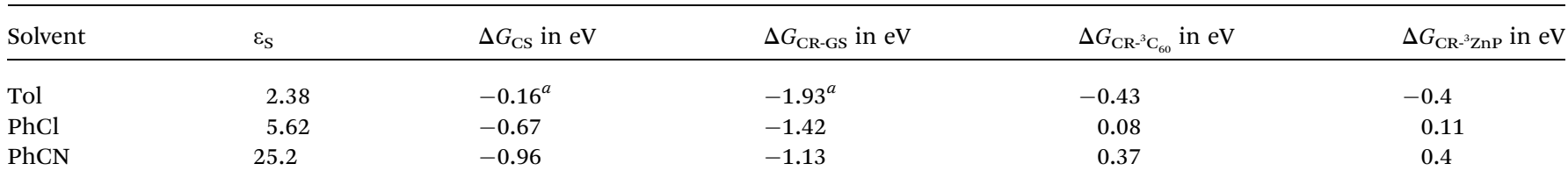

${ }^{a}$ The dielectric continuum model, which was employed to calculate the driving forces, overestimates the influence of low polarity solvents. 


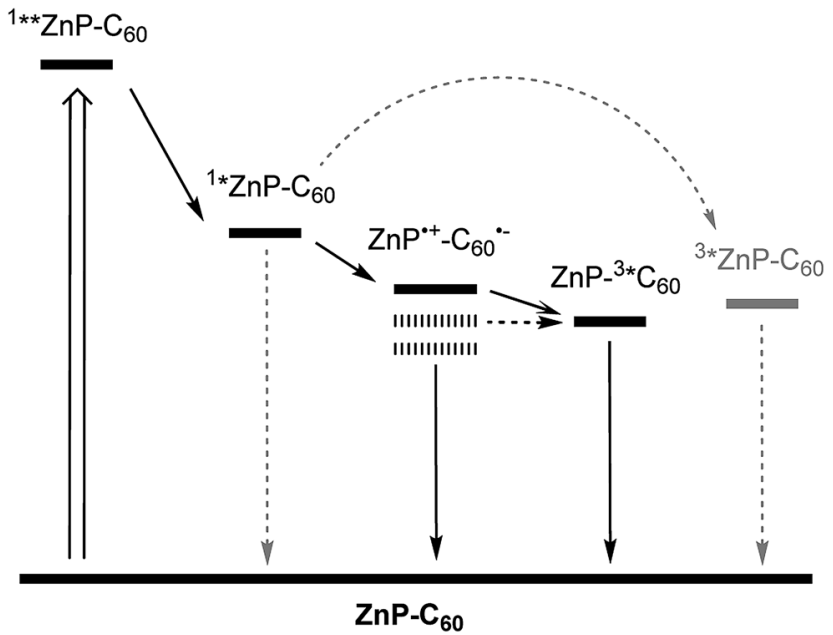

Fig. 2 Summary of the deactivation pathways for photoexcited 1Zn in toluene (bold bars). Lower CSS energies for chlorobenzene and benzonitrile indicated by dashed bars. Minor pathways are indicated by dashed lines.

Even from the contour plots across the 400 to $1200 \mathrm{~nm}$ range at time delays up to $100 \mu \mathrm{s}$, it is evident that the $410 \mathrm{~nm}$ fingerprint of the one-electron oxidized porphyrin $\left(\mathrm{ZnP}^{\cdot+}\right)$ and the $1010 \mathrm{~nm}$ fingerprint of the one-electron reduced fullerene $\left(\mathrm{C}_{60}{ }^{-}\right)$show vastly different lifetimes in apolar toluene (Fig. 3) and polar benzonitrile (Fig. 4). Concomitant with the decay of theZnP ${ }^{+}$and $\mathrm{C}_{60}{ }^{--}$signatures at 410/450/650 and $1010 \mathrm{~nm}$, respectively, is the population of the $\mathrm{C}_{60}$ triplet excited state in the form of the $700 \mathrm{~nm}$ fingerprint (also see ESI, $\uparrow$ Fig. S4). Based on the intensity of this signal, the quantum yield of ${ }^{3}{ }^{*} \mathrm{C}_{60}$ is estimated to be $20 \%$ in toluene, around $5 \%$ in chlorobenzene, and $0 \%$ in benzonitrile. The time absorption profiles at 410 and $1010 \mathrm{~nm}$ provided in Fig. 5 and 6 clearly depict the dynamics of the charge recombination processes. A clear monoexponential formation of the charge-separated state was observed-in all solvents and in all solvent combinations (see ESI, $\uparrow$ Fig. S30S39).

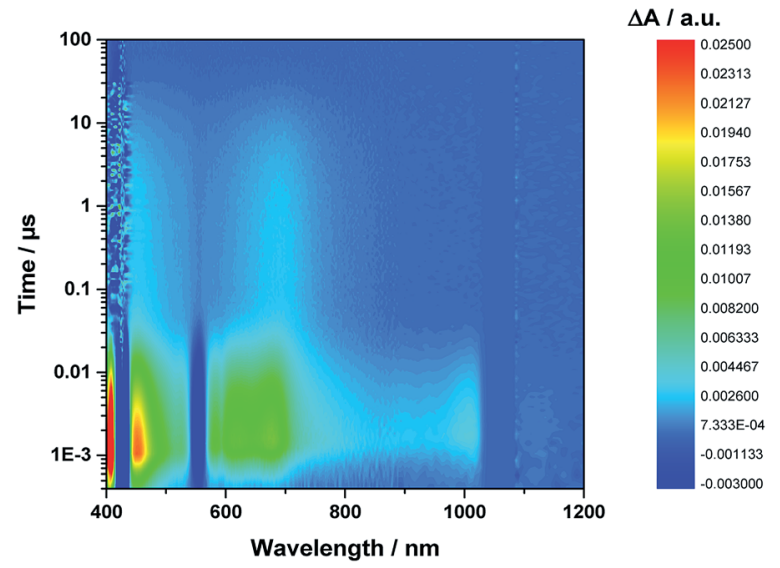

Fig. 3 Contour plot of transient absorption measurements of $1 \mathrm{Zn}$ in toluene-please note the detector change at around $900 \mathrm{~nm}$ and the probe fundamental at around $1064 \mathrm{~nm}$.

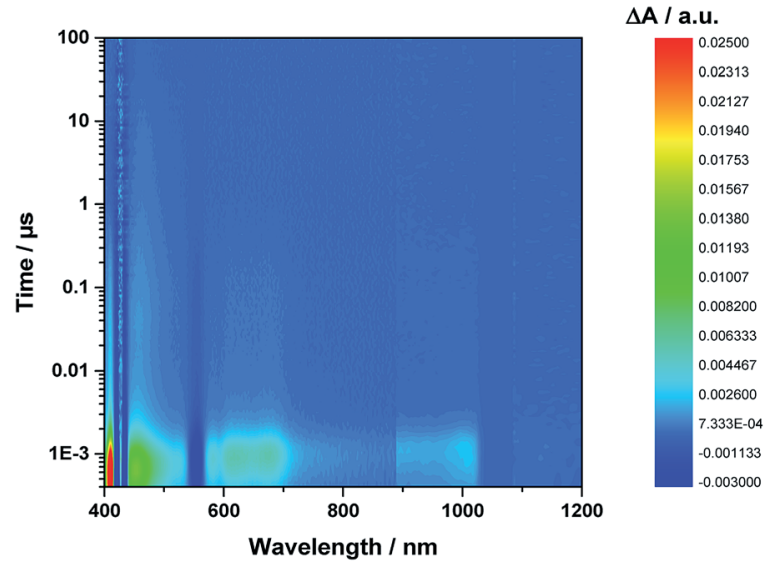

Fig. 4 Contour plot of transient absorption measurements of $1 \mathrm{Zn}$ in benzonitrile-please note the detector change at around $900 \mathrm{~nm}$ and the probe fundamental at around $1064 \mathrm{~nm}$.

A closer look at the decay curves reveals that the chargeseparated state $\left(\mathrm{ZnP}^{{ }^{+}-}-\mathrm{C}_{60}{ }^{--}\right)$decay is biphasic in benzonitrile with a short-lived ( $<1 \mathrm{~ns})$ and a long-lived ( $\sim 280 \mathrm{~ns}$ ) component. In contrast, the decay is mono-phasic in toluene, with a lifetime that is longer than the short-lived component in benzonitrile. All the excited/charge-separated state lifetimes for $\mathbf{1 Z n}$ are listed in Table 2; those for $\mathbf{1}$ are provided in the ESI, $\dagger$ Table S3.

In other words, in toluene a short-lived charge-separated state is formed, which then deactivates via ${ }^{3} \mathrm{C}_{60}$ to the ground state, whereas in benzonitrile, an additional long-lived chargeseparated state, accounting for approximately $10 \%$ of the amplitude of the fingerprints, is registered (also see ESI, $\dagger$ Fig. S5). A rationale for the short-lived component is based on the Marcus theory for electron transfer, in which lowering the energy of the charge-separated state in benzonitrile relative to toluene goes hand-in-hand with a faster deactivation. A similar consideration fails, however, to explain our observation of the long-lived component in benzonitrile. ${ }^{57}$ The coexistence of

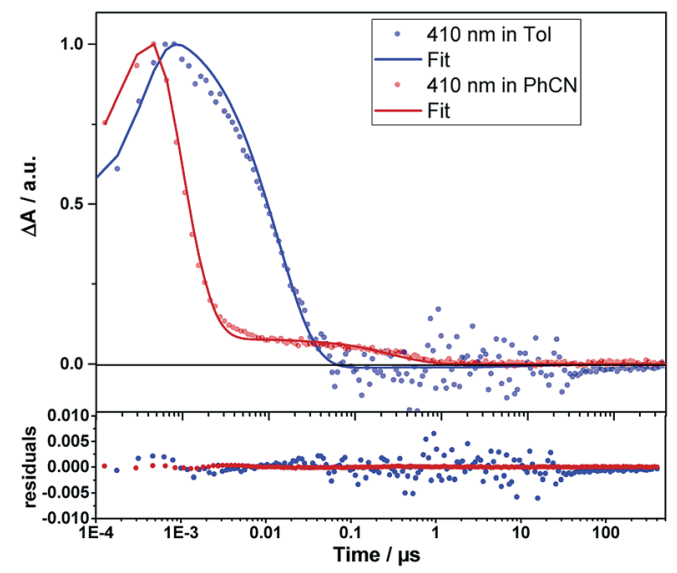

Fig. 5 Time traces (dots) and the corresponding fits derived from GTA (lines) of the $\mathrm{ZnP}^{\cdot+}$ signal of $1 \mathrm{Zn}$ in toluene and benzonitrile. Bottom: fit residuals. 


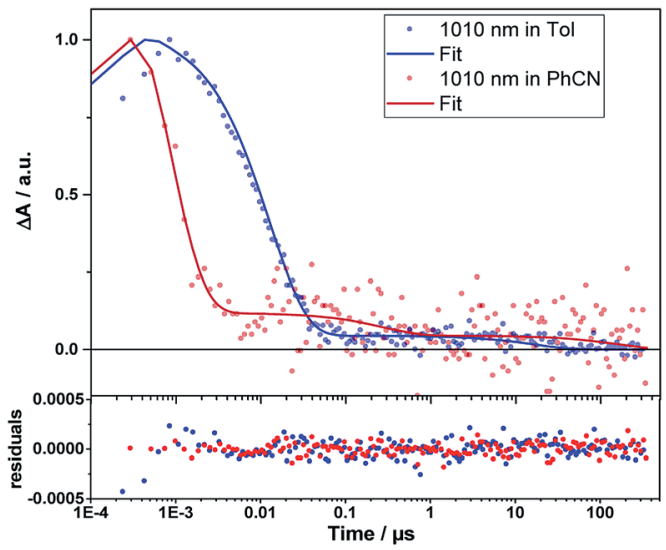

Fig. 6 Time traces (dots) and the corresponding fits derived from GTA (lines) of the $\mathrm{C}_{60}{ }^{\circ-}$ signal of $1 \mathrm{Zn}$ in toluene and benzonitrile. Bottom: fit residuals.

singlet and triplet CSS as a means to rationalize the short- and long-lived components is ruled out, as CS implies the conservation of spin..$^{58}$ Alternatively, CS from the triplet excited states of $\mathrm{ZnP}$ or $\mathrm{C}_{60}$ to form a triplet CSS would be energetically feasible in benzonitrile (see Table 1). However, the population of the triplet excited states of either $\mathrm{ZnP}$ or $\mathrm{C}_{60}$ is negligible due to the highly efficient CS starting from the $\mathrm{ZnP}$ singlet excited state. Even an interconversion between singlet CSS and triplet CCS is unlikely. In short, any of the aforementioned pathways toward a triplet CSS are unlikely to play a role.

An alternative scenario, namely a change in electron donoracceptor distance, must be considered. In particular, an increased spatial separation ${ }^{59}$ between electron donor and acceptor is likely induced by a movement of the porphyrin away from the fullerene via shuttling along the rotaxane's axle. Theoretical calculations reveal that the resulting difference in electron donor acceptor distance (edge to edge) is up to $>8 \AA$ (see ESI, $\dagger$ Fig. S9). Coordination of the Zn-center constitutes a bottleneck. For example, triazole of the axle is likely to form a coordination bond with the Zn-center, which, in turn, locks the position of the porphyrin close to the triazole-vide infra. Coordinating solvents such as benzonitrile are unlikely to trigger shuttling along the rotaxane axle because, in the ground state, simultaneous coordination of triazole and benzonitrile or even displacement of triazole by benzonitrile is highly unlikely. ${ }^{60}$ In stark contrast, oxidation of $\mathrm{ZnP}$ by means of charge separation results in a notable distortion of the $\mathrm{ZnP}$ scaffold, for which either $\mathrm{S}_{4}$-saddle or $\mathrm{D}_{2}$-ruffle geometries are reported. ${ }^{61,62}$ Oxidation also renders ZnP more electron deficient and more electrophilic. ${ }^{63}$ Distortion of the $\mathrm{ZnP}$ scaffold facilitates the bottom-side attack on the $\mathrm{Zn}$ center. Both of these facts lead to a scenario in which decoordination of the weak electron donating triazole and subsequent coordination of a more electron donating solvent molecule $^{64}$ is favored. In other words, the $\mathrm{ZnP}$ shuttle becomes mobile along the axle only after its oxidation by means of a photoinduced charge transfer, and in the presence of a coordinating agent. ${ }^{65}$

The presence of $10^{-3} \mathrm{M}$ pyridine in the toluene solution of $1 \mathrm{Zn}\left(5 \times 10^{-5} \mathrm{M}\right)$ induces the same effects that were discussed for benzonitrile. Most notably, two lifetimes were observed for 1Zn (see Fig. S10-S12, ESI $\dagger$ ). However, the first lifetime, contributing to at least $90 \%$ of the signal amplitude, is drastically shortened, whereas the other remains comparable to that in toluene in the absence of pyridine.

This implies that, once the shuttle is mobile, the solvent polarity controls the directionality of the shuttling along the axle. In apolar toluene and in the presence of coordinating pyridine, the one-electron oxidized porphyrin $\left(\mathrm{ZnP}^{\cdot+}\right)$ is drawn directionally towards the one-electron reduced fullerene $\left(\mathrm{C}_{60}{ }^{\cdot-}\right)$. This leads to a drastically faster charge recombination of $1.7 \mathrm{~ns}$ as a major component and a nearly unchanged charge recombination of $9.42 \mathrm{~ns}$ as a minor component (indicating the fraction of 1Zn where the porphyrin remains anchored to the triazole). In polar benzonitrile, the solvent polarity is high enough to allow for random motion along the axle, i.e. decreasing and/or increasing the electron donor-acceptor distance. The largely decreased charge recombination of $278 \mathrm{~ns}$ cannot be explained by just the Marcus theory of charge transfer without considering an increased electron donor-acceptor separation. In contrast, the faster charge recombination of 0.76 $\mathrm{ns}$ is even shorter than that found in toluene when pyridine is present and is easily rationalized by the Marcus theory for charge transfer with dynamics that are placed in the inverted region of the Marcus parabola-see Table 1. Implicit are the same short distances between the one-electron oxidized porphyrin $\left(\mathrm{ZnP}^{\cdot+}\right)$ and the one-electron reduced fullerene $\left(\mathrm{C}_{60}{ }^{-}\right)$as postulated in toluene.

To confirm our hypothesis, reference experiments were conducted with free base porphyrin rotaxane 1 (ESI, $\dagger$ Fig. S16-

Table 2 Summary of excited state lifetimes determined by means of GTA for $1 \mathrm{Zn}$ in various solvents

\begin{tabular}{|c|c|c|c|c|c|}
\hline Lifetimes of observed species & Toluene & Toluene + pyridine & Chlorobenzene & Chlorobenzene + pyridine & Benzonitrile \\
\hline $1 * * \mathrm{ZnP}-\mathrm{C}_{60} / \mathrm{ps}$ & 0.44 & 0.59 & 1.14 & $-^{a}$ & 0.64 \\
\hline $1 * \mathrm{ZnP}-\mathrm{C}_{60} / \mathrm{ps}$ & 20.8 & 28.2 & 25.5 & 24.5 & 26.4 \\
\hline $\mathrm{ZnP}^{\cdot+}-\mathrm{C}_{60} \cdot{ }^{-}$long $/ \mathrm{ns}$ & $-^{a}$ & 9.42 & $-^{a}$ & 256 & 278 \\
\hline $\mathrm{ZnP}-{ }^{3}{ }^{*} \mathrm{C}_{60} / \mu \mathrm{s}$ & 16.4 & 12.7 & 13.3 & 14.2 & $-^{a}$ \\
\hline${ }^{3} * \mathrm{ZnP}-\mathrm{C}_{60} / \mu \mathrm{s}$ & $-^{a}$ & $-^{a}$ & 200 & 166 & 164 \\
\hline
\end{tabular}

${ }^{a}$ State not observed. 
S29). Despite the fact that the driving forces for charge separation (see Table S2 $\dagger$ ) are up to $0.4 \mathrm{eV}$ smaller in 1 than in $\mathbf{1 Z n}$, charge separation (see Table $\mathrm{S} 3 \dagger$ ) is slowed down by only a few ps. Notably, the lack of a coordinating Zn-center in $\mathbf{1}$ leaves the shuttle free to move along the axle. A combination of $\pi-\pi$ and charge transfer interactions, to name just a few, results in short electron donor-acceptor distances rather than large ones. In turn, charge separation and recombination are both accelerated. ${ }^{66}$ The triplet quantum yields correlate well with the underlying driving forces (Table S2, ESI $\dagger$ ). However, solvent variation does not induce multiple CSS components in the excited state deactivation of $\mathbf{1}$. This is quite different from the observations for $\mathbf{1 Z n}$. In other words, no triggered release of the porphyrin shuttle is possible in $\mathbf{1}$ due to its lack of a coordinating metal center.

\section{Structural investigations}

Considering the lifetime differences and the observation of a long-lived charge-separated state for $\mathbf{1 Z n}$ in the presence of coordinating solvents, the influence of the latter was investigated. The location of the dumbbell with respect to the porphyrin in the presence of a coordinating solvent $(10 \%$ pyridine- $d_{5}$ in benzene- $d_{6}$ ) and of a non-coordinating solvent (benzene- $d_{6}$ ) was deduced from 1D- and 2D- $\left({ }^{1} \mathrm{H}-\mathrm{NMR}\right)$ studies (see ESI, $\uparrow$ Fig. S40-S53). Fig. 7 depicts the postulated structures in solution.

In benzene- $d_{6}$, the triazole subunit of $\mathbf{1 Z n}$ is coordinated to the $\mathrm{Zn}$-center and stabilized by a hydrogen bond of the triazole with the nitrogen atoms of the phenanthroline, as indicated by the downfield location of the triazole proton $\mathrm{H}_{\mathrm{i}}$ at $9.82 \mathrm{ppm}$. In the presence of $10 \%$ pyridine- $d_{5}$, which binds to the Zn-center opposite to the triazole, the triazole is relocated and sits outside of the phenanthroline pocket. Still, it is above the

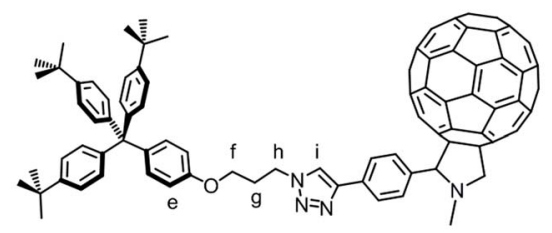

\begin{tabular}{|c|c|c|c|c|c|c|c|c|}
\hline Solvent & $\mathrm{H}$ & e & $f$ & $g$ & $h$ & i & 8 & 9 \\
\hline $\mathrm{C}_{6} \mathrm{D}_{6}$ & $\begin{array}{c}\delta \\
(\mathrm{ppm})\end{array}$ & 5.70 & 2.48 & -1.72 & -0.50 & $\begin{array}{c}9.82 \\
\text { (H-bond) }\end{array}$ & 6.42 & 6.11 \\
\hline $\begin{aligned} & C_{6} D_{6} \\
+ & 10 \% \mathrm{Py}\end{aligned}$ & $\begin{array}{c}\delta \\
(\mathrm{ppm})\end{array}$ & 4.40 & $\begin{array}{l}-1.07 \\
-0.93\end{array}$ & $\begin{array}{c}0.89 \\
(\mathrm{H}-\text {-bond })\end{array}$ & $\begin{array}{l}-3.26 \\
-3.25\end{array}$ & 4.92 & 6.82 & 6.99 \\
\hline
\end{tabular}

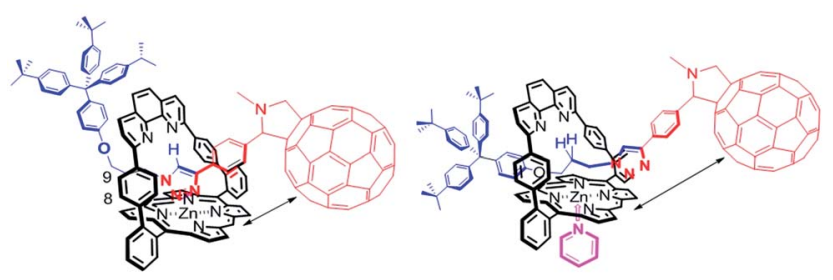

Fig. 7 Comparison of the chemical shifts and position of the dumbbell of $1 \mathrm{Zn}$ in benzene- $d_{6}$ (bottom left) and in benzene- $d_{6}+10 \%$ pyridine$d_{5}$ (bottom right). shielding cone of the porphyrin as seen by the upfield shift of $\mathrm{H}_{\mathrm{i}}$ to $4.92 \mathrm{ppm}$. Deshielding of $\mathrm{H}_{8}$ and $\mathrm{H}_{9}$ corroborated that the triazole does sit outside of the phenanthroline pocket in pyridine- $d_{5}$. In benzene- $d_{6}$, these two protons are discernable at higher fields due to the influence of the triazole ring current.

Major differences of the chemical shifts also evolved for the alkyl protons. A coordinating solvent significantly affects the positioning of the dumbbell's propyl chain relative to the strapped porphyrin. Fig. 7 summarizes all the relevant chemical shifts stemming from the $\mathbf{1 Z n}$ protons in benzene- $d_{6}$ and in a mixture of $10 \%$ pyridine- $d_{5}$ in benzene- $d_{6}$.

Compared to their chemical shifts in benzene- $d_{6}$, the alkyl protons $\mathrm{H}_{\mathrm{f}}$ and $\mathrm{H}_{\mathrm{h}}$ are strongly shielded and appear as diastereotopic protons in the presence of pyridine- $d_{5}$. In contrast, $\mathrm{H}_{\mathrm{g}}$ protons are deshielded in pyridine- $d_{5}$. Taking the aforementioned into account implies that in the presence of a coordinating solvent the propyl chain is positioned above the porphyrin with possible hydrogen bonding interactions between $\mathrm{H}_{\mathrm{g}}$ and the phenanthroline nitrogen atoms. With respect to the position of the dumbbell, when a coordinating solvent is present, it is similar to what has been derived from the crystal structure (see ESI, $\uparrow$ Fig. S54) for an analogue of $1 Z n$ featuring two triaryl stoppers.

By correlating the observations made in the NMR studies with the results of the photophysics, the following conclusions are reached. In solution, shuttling in $\mathbf{1 Z n}$ is enabled by either coordinating solvents or a coordinating additive. Oxidation induces a distortion of the porphyrin scaffold and, in turn, facilitates easy access to the $\mathrm{Zn}$-center. This consequently induces triazole-decoordination from the $\mathrm{Zn}$-center as a starting point for directional or random shuttling in apolar or polar solvents, respectively.

\section{Conclusions}

In this work on rotaxanes comprising a strapped-porphyrin as a ring molecule and a dumbbell bearing one fullerene stopper, coordination forces are crucial for the excited state behavior. Distinct differences in the lifetime of the charge-separated state and the presence of more than a single lifetime were observed in 1Zn. Here, the coordinating properties and the polarity of the solvent have the strongest impact. For example, in apolar, non-coordinating toluene, a single lifetime was found for the charge-separated state, whereas in polar, coordinating PhCN, a short-lived and a long-lived charge-separated state evolved. In toluene and $\mathrm{PhCl}$, these effects were also induced when a coordinating species, such as pyridine, was added to $\mathbf{1 Z n}$.

Depending on the solvent polarity, the shuttling is either directional or random. In apolar toluene and in the presence of pyridine, Coulombic interactions in the $\mathrm{ZnP}^{\cdot+}-\mathrm{C}_{60}{ }^{\cdot-}$ radical ion pair dominate and, in turn, force a close proximity between the oxidized porphyrin and the reduced fullerene. This sets up the means for a directional molecular shuttling, which results in a drastically reduced lifetime of the charge-separated state. In highly polar benzonitrile, shuttling is random and allows the 
fullerene anion to move further away from the porphyrin radical cation in 1Zn. This enables the system to overcome the barrier of Coulombic attractions. As such, larger porphyrin-to-fullerene distances go hand-in-hand with a longer lifetime of the chargeseparated state in a high-polarity coordinating solvent relative to that in either non-coordinating solvents or low-polarity solvents. Independent confirmation of our hypothesis came from the absence of a longer and/or a shorter-lived chargeseparated state in the presence of a coordinating solvent in analogous experiments with 1, which features a strapped freebase porphyrin, without porphyrin-triazole interactions, rather than a zinc porphyrin.

Our results emphasize the importance of coordination interactions and their modulation in the excited state of a zincporphyrin rotaxane. To gain further insight, rotaxanes with longer, more rigid axles, which should enhance the effects on the distribution of lifetimes, are currently being designed and studied in our laboratories. Finally, a porphyrin with a metal center that binds pyridine more strongly than zinc, such as rhodium, could exhibit interesting behavior.

\section{Conflicts of interest}

There are no conflicts to declare.

\section{Acknowledgements}

M. V. thanks the French Ministry of Research for a PhD fellowship. This work was partially funded by JST-ANR grant ANR-14-JTIC-0002-01 (MECANO), JSPS KAKENHI (Grant Number JP15H05804 in Innovative Areas "Precisely Designed Catalysts with Customized Scaffolding"), Deutsche Forschungsgemeinschaft DFG (SFB953 Synthetic Carbon Allotropes), and the State of Bavaria (SolTech).

\section{Notes and references}

1 The Nobel Prize in Chemistry 2016, Nobel Media AB, 2018.

2 C. Dietrich-Buchecker, J.-P. Sauvage and J.-P. Kintzinger, Tetrahedron Lett., 1983, 24, 5095-5098.

3 S. Silvi, M. Venturi and A. Credi, J. Mater. Chem., 2009, 19, 2279.

4 N. Ponnuswamy, F. B. L. Cougnon, J. M. Clough, G. D. Pantoş and J. K. M. Sanders, Science, 2012, 338, 783-785.

5 J. J. Danon, A. Krüger, D. A. Leigh, J.-F. Lemonnier, A. J. Stephens, I. J. Vitorica-Yrezabal and S. L. Woltering, Science, 2017, 355, 159-162.

6 N. Armaroli, V. Balzani, J.-P. Collin, P. Gaviña, J.-P. Sauvage and B. Ventura, J. Am. Chem. Soc., 1999, 121, 4397-4408.

7 R. Ballardini, V. Balzani, A. Credi, M. T. Gandolfi and M. Venturi, Acc. Chem. Res., 2001, 34, 445-455.

8 S. Durot, V. Heitz, A. Sour and J.-P. Sauvage, Top. Curr. Chem., 2014, 354, 35-70.

9 C. J. Bruns and J. F. Stoddart, Acc. Chem. Res., 2014, 47, 21862199.

10 M. Xue, Y. Yang, X. Chi, X. Yan and F. Huang, Chem. Rev., 2015, 115, 7398-7501.
11 G. Mancini, C. Zazza, M. Aschi and N. Sanna, Phys. Chem. Chem. Phys., 2011, 13, 2342-2349.

12 N. K. Jena and N. A. Murugan, J. Phys. Chem. C, 2013, 117, 25059-25068.

13 S. S. Andersen, A. I. Share, B. L. C. Poulsen, M. Kørner, T. Duedal, C. R. Benson, S. W. Hansen, J. O. Jeppesen and A. H. Flood, J. Am. Chem. Soc., 2014, 136, 6373-6384.

14 A. V. Leontiev, C. J. Serpell, N. G. White and P. D. Beer, Chem. Sci., 2011, 2, 922.

15 T. A. Barendt, I. Rašović, M. A. Lebedeva, G. A. Farrow, A. Auty, D. Chekulaev, I. V. Sazanovich, J. A. Weinstein, K. Porfyrakis and P. D. Beer, J. Am. Chem. Soc., 2018, 140, 1924-1936.

16 A. Tron, I. Pianet, A. Martinez-Cuezva, J. H. R. Tucker, L. Pisciottani, M. Alajarin, J. Berna and N. D. McClenaghan, Org. Lett., 2017, 19, 154-157.

17 S. Garaudée, S. Silvi, M. Venturi, A. Credi, A. H. Flood and J. F. Stoddart, ChemPhysChem, 2005, 6, 2145-2152.

18 R. A. Bissell, E. Córdova, A. E. Kaifer and J. F. Stoddart, Nature, 1994, 369, 133-137.

19 J. Baggerman, N. Haraszkiewicz, P. G. Wiering, G. Fioravanti, M. Marcaccio, F. Paolucci, E. R. Kay, D. A. Leigh and A. M. Brouwer, Chem.-Eur. J., 2013, 19, 5566-5577.

20 Z. Zhang, C. Han, G. Yu and F. Huang, Chem. Sci., 2012, 3, 3026.

21 Y. Liu, C. Chipot, X. Shao and W. Cai, J. Phys. Chem. C, 2016, 120, 6287-6293.

22 A. C. Benniston and A. Harriman, Angew. Chem., Int. Ed. Engl., 1993, 32, 1459-1461.

23 H. Murakami, A. Kawabuchi, K. Kotoo, M. Kunitake and N. Nakashima, J. Am. Chem. Soc., 1997, 119, 7605-7606.

24 J.-P. Sauvage, Acc. Chem. Res., 1998, 31, 611-619.

25 J. A. Wytko, R. Ruppert, C. Jeandon and J. Weiss, Chem. Commun., 2018, 54, 1550-1558.

26 H. Imahori and S. Fukuzumi, Adv. Funct. Mater., 2004, 14, 525-536.

27 C. Luo, D. M. Guldi, H. Imahori, K. Tamaki and Y. Sakata, J. Am. Chem. Soc., 2000, 122, 6535-6551.

28 J. D. Megiatto, A. Antoniuk-Pablant, B. D. Sherman, G. Kodis, M. Gervaldo, T. A. Moore, A. L. Moore and D. Gust, Proc. Natl. Acad. Sci. U.S.A., 2012, 109, 15578-15583.

29 M. Wolf, A. Herrmann, A. Hirsch and D. M. Guldi, J. Am. Chem. Soc., 2017, 139, 11779-11788.

30 M. Wolf, C. Villegas, O. Trukhina, J. L. Delgado, T. Torres, N. Martín, T. Clark and D. M. Guldi, J. Am. Chem. Soc., 2017, 139, 17474-17483.

31 D. I. Schuster, J. Org. Chem., 2013, 78, 6811-6841.

32 K. Li, D. I. Schuster, D. M. Guldi, M. Á. Herranz and L. Echegoyen, J. Am. Chem. Soc., 2004, 126, 3388-3389.

33 A. S. D. Sandanayaka, N. Watanabe, K.-I. Ikeshita, Y. Araki, N. Kihara, Y. Furusho, O. Ito and T. Takata, J. Phys. Chem. $B, 2005,109,2516-2525$.

34 A. S. D. Sandanayaka, H. Sasabe, Y. Araki, N. Kihara, Y. Furusho, T. Takata and O. Ito, J. Phys. Chem. A, 2010, 114, 5242-5250. 
35 A. Mateo-Alonso, C. Ehli, G. M. A. Rahman, D. M. Guldi, G. Fioravanti, M. Marcaccio, F. Paolucci and M. Prato, Angew. Chem., Int. Ed., 2007, 46, 3521-3525.

36 A. S. D. Sandanayaka, H. Sasabe, Y. Araki, N. Kihara, Y. Furusho, T. Takata and O. Ito, Aust. J. Chem., 2006, 59, 186.

37 M. R. Panman, P. Bodis, D. J. Shaw, B. H. Bakker, A. C. Newton, E. R. Kay, D. A. Leigh, W. J. Buma, A. M. Brouwer and S. Woutersen, Phys. Chem. Chem. Phys., 2012, 14, 1865-1875.

38 B. Delavaux-Nicot, H. Ben Aziza, I. Nierengarten, T. Minh Nguyet Trinh, E. Meichsner, M. Chessé, M. Holler, R. Abidi, E. Maisonhaute and J.-F. Nierengarten, Chem.Eur. J., 2018, 24, 133-140.

39 Y. Miyazaki, C. Kahlfuss, A. Ogawa, T. Matsumoto, J. A. Wytko, K. Oohora, T. Hayashi and J. Weiss, Chem.Eur. J., 2017, 23, 13579-13582.

40 H. Zheng, W. Zhou, J. Lv, X. Yin, Y. Li, H. Liu and Y. Li, Chem.-Eur. J., 2009, 15, 13253-13262.

41 K.-H. Le Ho, I. Hijazi, L. Rivier, C. Gautier, B. Jousselme, G. de Miguel, C. Romero-Nieto, D. M. Guldi, B. Heinrich, B. Donnio and S. Campidelli, Chem.-Eur. J., 2013, 19, 11374-11381.

42 J. A. Wytko, E. Graf and J. Weiss, J. Org. Chem., 1992, 57, 1015-1018.

43 J. Froidevaux, P. Ochsenbein, M. Bonin, K. Schenk, P. Maltese, J.-P. Gisselbrecht and J. Weiss, J. Am. Chem. Soc., 1997, 119, 12362-12363.

44 C. H. Kirksey, P. Hambright and C. B. Storm, Inorg. Chem., 1969, 8, 2141-2144.

45 M. Nappa and J. S. Valentine, J. Am. Chem. Soc., 1978, 100, 5075-5080.

46 C. B. Storm, A. H. Turner and M. B. Swann, Inorg. Chem., 1984, 23, 2743-2746.

47 G. Szintay and A. Horváth, Inorg. Chim. Acta, 2000, 310, 175182.

48 M. A. Bobrik and F. A. Walker, Inorg. Chem., 1980, 19, 33833390.

49 D. M. Guldi, C. Luo, M. Prato, A. Troisi, F. Zerbetto, M. Scheloske, E. Dietel, W. Bauer and A. Hirsh, J. Am. Chem. Soc., 2001, 123, 9166-9167.
50 A. A. Maryott and E. R. Smith, Table of dielectric constants of pure liquids, National Bureau of Standards, Washington D.C., 1951.

51 D. M. Guldi, C. Luo, M. Prato, E. Dietel and A. Hirsch, Chem. Commun., 2000, 373-374.

52 J. Fajer, D. C. Borg, A. Forman, D. Dolphin and R. H. Felton, J. Am. Chem. Soc., 1970, 92, 3451-3459.

53 N. Carnieri and A. Harriman, Inorg. Chim. Acta, 1982, 62, 103-107.

54 C. A. Reed and R. D. Bolskar, Chem. Rev., 2000, 100, 10751120.

55 J. J. Snellenburg, S. P. Laptenok, R. Seger, K. M. Mullen and I. H. M. van Stokkum, J. Stat. Software, 2012, 49, 3.

56 K. M. Mullen and I. H. M. van Stokkum, J. Stat. Software, 2007, 18, 3 .

57 At room temperature porphyrin-fullerene conformations are indistinguishable. Instead, all possible conformers of $\mathrm{C}_{60}$ relative to the porphyrin (e.g. cis or trans) coexist in solution.

58 J. T. Buck, A. M. Boudreau, A. DeCarmine, R. W. Wilson, J. Hampsey and T. Mani, Chem, 2018, 5, 138-155.

59 M. Kuss-Petermann and O. S. Wenger, J. Am. Chem. Soc., 2016, 138, 1349-1358.

60 L. Favereau, A. Cnossen, J. B. Kelber, J. Q. Gong, R. M. Oetterli, J. Cremers, L. M. Herz and H. L. Anderson, J. Am. Chem. Soc., 2015, 137, 14256-14259.

61 H. Song, N. P. Rath, C. A. Reed and W. R. Scheidt, Inorg. Chem., 1989, 28, 1839-1847.

62 R. W. Scheidt, JBIC, J. Biol. Inorg. Chem., 2001, 6, 727-732.

63 A. S. Hinman and B. J. Pavelich, J. Electroanal. Chem., 1989, 269, 53-61.

64 N. S. Lebedeva, A. I. Vyugin, N. A. Pavlycheva, E. V. Parfenyuk and O. I. Davidova, Thermochim. Acta, 2002, 390, 179-186.

65 Pure non-coordinating solvents such as toluene or chlorobenzene disable the shuttling (for results in chlorobenzene see ESI, $\uparrow$ Fig. S6-S8).

66 The latter is further accelerated by the fact that the triplet excited states of $\mathrm{C}_{60}$ and/or $\mathrm{H}_{2} \mathrm{P}$ evolve as products of charge recombination. 